\title{
Exon Array Biomarkers for the Differential Diagnosis of Schizophrenia and Bipolar Disorder
}

\author{
Marquis Philip Vawter ${ }^{\mathrm{a}}$ Robert Philibert ${ }^{\mathrm{b}}$ Brandi Rollins $^{\mathrm{a}} \quad$ Patricia L. Ruppel $^{\mathrm{c}}$ \\ Terry W. Osborn ${ }^{\text {d }}$ \\ ${ }^{a}$ Functional Genomics Laboratory, Department of Psychiatry, University of California, Irvine, CA, USA; \\ ${ }^{b}$ Department of Psychiatry, University of lowa, lowa City, IA, USA; 'Innovative Analytics, Inc., Kalamazoo, MI, USA; \\ dLaguna Diagnostics, LLC, The Villages, FL, USA
}

\section{Keywords}

Biomarker · Bipolar I disorder · Schizophrenia

\begin{abstract}
This study developed potential blood-based biomarker tests for diagnosing and differentiating schizophrenia (SZ), bipolar disorder type I (BD), and normal control (NC) subjects using mRNA gene expression signatures. A total of 90 subjects ( $n=30$ each for the three groups of subjects) provided blood samples at two visits. The Affymetrix exon microarray was used to profile the expression of over 1.4 million probesets. We selected potential biomarker panels using the temporal stability of the probesets and also back-tested them at two different visits for each subject. The 18-gene biomarker panels, using logistic regression modeling, correctly differentiated the three groups of subjects with high accuracy across the two different clinical visits (83-88\% accuracy). The results are also consistent with the actual data and the "leaveone-out" analyses, indicating that the models should be predictive when applied to independent data cohorts. Many of the $S Z$ and BD subjects were taking antipsychotic and mood stabilizer medications at the time of blood draw, raising the possibility that these drugs could have affected some of the
\end{abstract}

differential transcription signatures. Using an independent Illumina data set of gene expression data from antipsychotic medication-free SZ subjects, the 18-gene biomarker panels produced a receiver operating characteristic curve accuracy greater than 0.866 in patients that were less than 30 years of age and medication free. We confirmed select transcripts by quantitative PCR and the nCounter ${ }^{\circledR}$ System. The episodic nature of psychiatric disorders might lead to highly variable results depending on when blood is collected in relation to the severity of the disease/symptoms. We have found stable trait gene panel markers for lifelong psychiatric disorders that may have diagnostic utility in younger undiagnosed subjects where there is a critical unmet need. The study requires replication in subjects for ultimate proof of the utility of the differential diagnosis.

(c) 2018 S. Karger AG, Basel

\section{Introduction}

Schizophrenia (SZ) and bipolar disorder (BD) are chronic, severe, and disabling brain disorders that affect about 1 and $2 \%$, respectively, of the US population aged 18 years and older. Despite moderately effective treat-

\section{KARGER}

(c) 2018 S. Karger AG, Basel

E-Mail karger@karger.com

www.karger.com/mnp
Dr. Marquis Philip Vawter

Department of Psychiatry and Human Behavior

University of California, Irvine, 2119 Gillespie

Irvine, CA 92697 (USA)

E-Mail mvawter@uci.edu 
ments such as antipsychotic medications and psychosocial interventions, people with $\mathrm{SZ}$ and BD often do not receive timely treatment because the disorder is not correctly recognized. As a result, patients experience multiple hospitalizations and incur socioeconomic disadvantages that can last for decades.

Ideally, successful diagnostic tests could address the significant clinical problem of early identification and differential diagnosis and permit more timely initiation of treatments. Currently, there are no approved clinical diagnostic tests for psychiatric disorders, with diagnosis and treatment being based on the patient's report of symptoms along with clinical observations. Consequently, clinicians frequently fail to recognize initial presentations of SZ and BD.

These failures may lead to devastating consequences. Following an initial episode of psychosis among individuals aged $16-30$ years, there is a 24 -fold increase in the risk of death in the following year [1]. This study points towards a lack of treatment $(61 \%$ did not receive any antipsychotic medication) after initial presentation with psychosis and even higher rates in those dying within 12 months of an initial episode of psychosis [1]. A panel of biomarkers would meet an unmet clinical need to help establish rapid and informative patient decisions. A clinical utility that might be derived from this work is establishing a biomarker panel for determining the psychosis risk state and which subjects may convert to SZ or BD [2]. An index of psychosis based upon a biomarker panel could be useful in evaluating a long-term response to treatments [3].

Conceivably, a panel of RNA biomarkers could address that need. A growing body of work has demonstrated the potential utility of RNA diagnostic tools with peripheral samples such as whole blood, peripheral blood mononuclear cells (PBMCs), and lymphoblastic cell lines in multiple studies of SZ and BD [4-12]. There have also been large studies that have used whole genome RNA expression to compare healthy controls and patients with disorders such as Alzheimer disease [13], autism [14], Down syndrome [15], epilepsy [16], Tourette syndrome [16], Huntington disease [17], Klinefelter syndrome [18], multiple sclerosis [19], smoking and major depression [20], panic disorder [21], posttraumatic stress disorder [22], and subjective social isolation (loneliness) [23]. The success in these studies suggests the possibility that similar approaches could be used to identify RNA profiles for the diagnosis of SZ and BD. Dysregulation of mRNA could potentially help to define sets of genes relevant to the diseases' pathophysiology and treatment or secondary to their causes.
We hypothesized that for SZ and BD there are unique and global sets of chronic, differentially expressed genes in blood for each disorder. Our hypothesis is based on the concept that circulating blood reflects the changing health of the body, i.e., the "sentinel principle" [24]. As blood circulates through the brain, communication occurs between cells in the blood and the brain [25]. Following a brain injury, neutrophils, macrophages, lymphocytes, and dendritic cells can extravasate into the brain from the blood [26]. These extravasated cells can induce changes in gene expression and proteins as reported in neuroimmunological studies $[27,28]$. In prior work using bloodbrain samples from the same subjects, about $20 \%$ of the transcriptome was expressed at comparable levels and significantly correlated in both tissues from the same subjects [29]. This correlation supports the idea that important biomarkers of either SZ or BD could be expressed peripherally, and these would also have a connection to the central modulation of neuroimmune responses. The advantages of a peripheral transcriptomic study are the ease of access to whole blood and the fact that immune genes are highly expressed. For example, multiple HLA region genes with genome-wide significance are expressed in peripheral blood samples, such as C4 [30] and HLA-DPA1 [31].

Although investigations of biomarkers for $\mathrm{SZ}$ and $\mathrm{BD}$ have been ongoing for at least a decade $[7,8,32]$, there are no widely replicated studies using peripheral blood gene expression [11, 33-42]. A recent mega-analysis of blood samples comparing SZ cases and controls was conducted on a total of 578 subjects in 9 studies. The mega-analysis of the blood transcriptome showed that 220 genes reached a Bonferroni-corrected level of significance [35], indicating the utility of analysis of the blood transcriptome for finding differentially expressed genes. The stability of this potential dysregulation has not been tested across different time points.

The objective of the present study was to test subjects at multiple time points by enrolling SZ $(n=30), \mathrm{BD}(n=$ $30)$, and normal control (NC; $n=30)$ subjects characterized at one clinical site to eliminate potential sources of variation. The expression levels of panels of genes were used to define with which disorder the patient was diagnosed with the highest likelihood. We have previously validated Tempus Blood RNA tubes and Affymetrix exon arrays in a study that measured the sources of variation for 8 healthy controls at 9 sequential blood draws every $6 \mathrm{~h} \mathrm{[29]} \mathrm{for} 54 \mathrm{~h}$. The resulting data showed that about $20 \%$ of the transcripts measured on the Affymetrix exon array did not significantly change over the 9 blood draws 


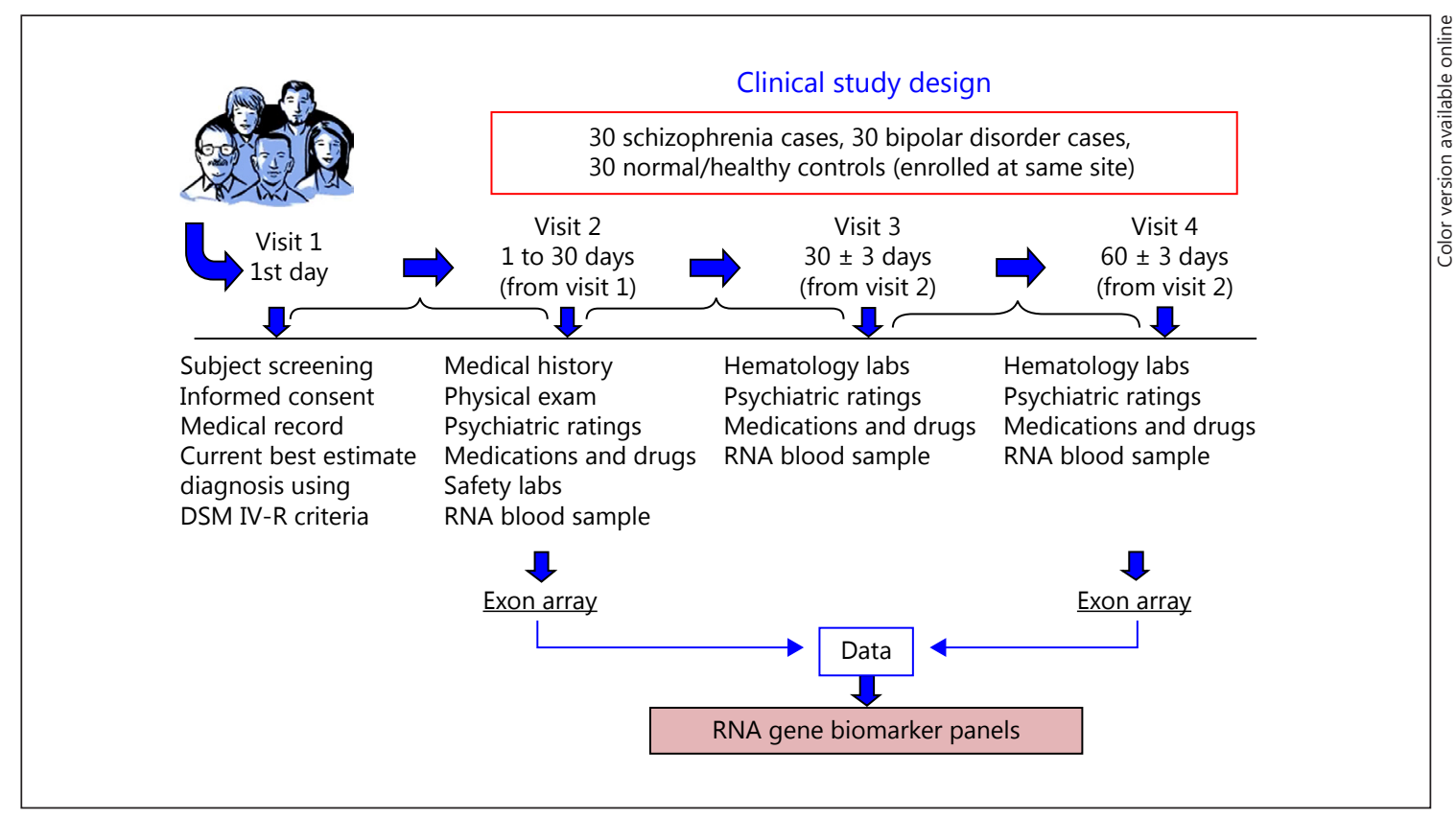

Fig. 1. Flowchart of the study: subject enrollment and RNA biomarker panel.

using Bonferroni correction during the 54 -h period. The remaining $80 \%$ of the transcripts had changed significantly during this 54-h experiment [29]. Taken together, it is expected that at least $20 \%$ of transcripts will be stable over longer periods of time and do not significantly fluctuate by the time of day of the blood draw.

These data reinforce the purpose of the present study to test whether stable expression of genes occurs over months instead of days, so that they can be used as biomarkers for SZ and BD for a differential diagnosis from controls and each other. In this study, RNA expression was measured by the Affymetrix exon array 1.0 ST for biomarker screening. Exon arrays have been widely used for the study of genetic variation in coding regions [4353]. Exon array findings correlate positively with RNASeq across most levels of transcript expression [54], and in some cases have less false-positive detection than RNASeq [55-57]. The analytical techniques for the exon arrays have been well established [56, 58-64].

\section{Methods}

\section{Subject Enrollment}

Subject enrollment occurred at a single clinical site at the University of Iowa. The University of Iowa and the Institutional Review Board approved the procedures in the study. The chronic SZ and BD type I outpatients aged 18-45 years provided consent for the study. All subjects (SZ, $n=30$; BD, $n=30$; and NC, $n=30$ ) met the DSM-IV-R criteria and completed the study. Clinical assessments included the Scale for the Assessment of Positive Symptoms and Scale for the Assessment of Negative Symptoms (SAPS, SANS), medications, and drugs for the SZ and BD subjects, as well as the Young Mania Rating Scale (YMRS) and Hamilton Rating Scale for Depression (HAM-D or HRSD) for the BD subjects. These neuropsychiatric assessment data were analyzed and are reported separately for state-biomarker relationships. The mental state examination for the NC subjects consisted of the Mini-Mental State Examination. The outline of the study is shown in Figure 1. The demographics of the $\mathrm{SZ}, \mathrm{BD}$, and NC subjects are shown in online supplementary Table 1 (for all online suppl. material, see www.karger.com/doi/10.1159/000485800) for the subjects' age, sex, duration of illness, and ethnicity.

Whole blood samples were collected in Tempus Blood RNA tubes (Thermo Fisher Scientific) from the SZ, BD, and NC subjects at 3 visits spanning 3 months. For this report, the Tempus tubes from visits 2 and 4 were extracted and RNA gene expression was measured using Affymetrix exon arrays for both visits on all 90 subjects. High-quality RNA was extracted from the Tempus tubes using the manufacturer's protocol, and quality was assessed on an Agilent Bioanalyzer using the RNA integrity number.

\section{Human Exon Array for Biomarker Profiling}

There are advantages to using the Affymetrix exon arrays [65] compared to whole transcriptome shotgun sequencing (RNA-Seq). At the time of sample collection, the cost factor was favorable for future clinical biomarker trials that would require hundreds of arrays compared to the cost of RNA-Seq for the entire validation. The processing time and data storage requirements as well are more favorable for a study this size using exon arrays. Although we and oth- 
ers have previously found that SNPs can affect probe hybridization and consequently alter expression $[44,51,52,66]$, those probesets with common SNPs were eliminated from the final data set. The exon arrays were run at the Functional Genomics Laboratory, University of California, using the manufacturer's protocol (Affymetrix, Santa Clara, CA, USA). The Functional Genomics Laboratory has run over 1,000 Affymetrix arrays with high-quality call rates.

\section{Data Analysis}

The Affymetrix exon array CEL files were imported into Partek Genomics using batch effect removal. The batch effect was based upon exon array scan dates, as usually 12 arrays were scanned in a single day. The mean intensity of probes was summarized at the probeset level. Probesets containing common SNPs were excluded from the import and downstream analysis. The resulting probesets were then median centered within each exon array sample individually $(n=180)$. A two-factor ANOVA was run for each probeset, using diagnosis, visit, and diagnosis $\times$ visit interaction. Visit was a repeated measure and was used to filter out genes that change significantly between visits. A false discovery rate (FDR) of $6 \times$ $10^{-8}$ was established for diagnosis effect based upon 835,000 probesets. Three filters were used to select probesets from the ANOVA results that passed the FDR for diagnosis: (1) the most significant $p$ values for $\mathrm{BD}$ compared to $\mathrm{NC}$; (2) the most significant $p$ values for $\mathrm{BD}$ compared to SZ; and (3) the most significant $p$ values for $S Z$ compared to NC. This resulted in a list of top probesets that was then reduced to probesets that mapped to known RefSeq genes. The top 100 RefSeq probesets for each of the three filters above were combined, and the resulting top 300 probesets were evaluated for biomarker signature.

\section{Biomarker Signature}

The modeling proceeded in four steps to select the most predictive panel of probesets out of the top 300 in each step for discriminating between groups:

- Step 1: NC versus BD + SZ

- $\quad$ Step 2: NC versus SZ

- Step 3: NC versus BD

- Step 4: SZ versus BD

Multivariate logistic regression modeling with forward stepwise selection (SAS PROC LOGISTIC) was used on the combined visit 2 and 4 data from the groups included in the step to select the probesets that were discriminating most strongly between the groups. We used forward stepwise regression to select probesets that differentiated two groups at a time (BD vs. SZ, BD vs. NC, and SZ vs. NC). A probeset was added to the model if the estimate was the most significant with $p<0.001$ and the resulting ROC AUC also retained statistical significance. Forward selection stopped when potential probesets were no longer statistically significant or did not improve the ROC AUC by more than $1 \%$. Processing for each step resulted in a subset of the 300 probesets where each probeset contributed to the model significantly and the panel represented the smallest number of probesets that had a very high diagnostic utility based on the ROC AUC.

Modeling for the diagnostic for each step was applied to the visit 2 data using the identified probesets. The optimal cut-point for discriminating between the groups based on the logistic model prediction was obtained by maximizing the Youden index $J$ [67], where:

$$
J=\text { True positive rate }-F P R \text {. }
$$

Table 1. Probesets that were found to reliably discriminate BD, SZ, and NC were assigned to known RefSeq transcripts

\begin{tabular}{|c|c|c|}
\hline $\begin{array}{l}\text { Biomarker panel } \\
\text { (comparisons) }\end{array}$ & $\begin{array}{l}\text { Affymetrix exon } \\
\text { microarray transcript ID }\end{array}$ & Gene \\
\hline $\mathrm{BD}-\mathrm{NC}$ & 2661992 & OXTR \\
\hline $\mathrm{BD}-\mathrm{NC}$ & 3195034 & PTGDS \\
\hline $\mathrm{BD}-\mathrm{NC}$ & 3333247 & FADS2 \\
\hline $\mathrm{BD}-\mathrm{NC}$ & 4048241 & HLA-DRB5 \\
\hline BD-SZ & 2661992 & OXTR \\
\hline BD-SZ & 3333247 & FADS2 \\
\hline BD-SZ & 3554818 & CRIP2 \\
\hline BD-SZ-NC & 2418570 & SLC44A5 \\
\hline BD-SZ-NC & 2545092 & HADHA \\
\hline BD-SZ-NC & 2647109 & CPA3 \\
\hline BD-SZ-NC & 2661992 & OXTR \\
\hline BD-SZ-NC & 2739160 & CCDC109B \\
\hline BD-SZ-NC & 2906720 & TREML4 \\
\hline BD-SZ-NC & 3063536 & TRIM4 \\
\hline BD-SZ-NC & 3195034 & PTGDS \\
\hline BD-SZ-NC & 3667890 & HPR \\
\hline BD-SZ-NC & 3846538 & EEF2 \\
\hline BD-SZ-NC & 3908149 & ZMYND8 \\
\hline SZ-NC & 2401347 & TCEA3 \\
\hline SZ-NC & 2418570 & SLC44A5 \\
\hline SZ-NC & 2660617 & IL5RA \\
\hline SZ-NC & 3329099 & GYLTL1B \\
\hline SZ-NC & 3766893 & DDX5 \\
\hline
\end{tabular}

BD, bipolar disorder; SZ, schizophrenia; NC, normal control.

The visit 2 prediction model was then applied to the visit 4 data to assess utility for the second set of data, which included stability over time.

Further evaluation for each of the four panels included "leaveone-out" cross-validation where one subject was sequentially left out of the logistic model fit using the remaining subjects and then the predictability of the model for the excluded subject was assessed. This tested whether there were outliers in the data set that were driving the model.

\section{Quantitative PCR}

Transcripts were selected for quantitative PCR (qPCR) validation based upon significant differences using the ANOVA filter. We selected transcripts that represented a combination of the most 
Table 2. Prediction model trained on combined visit 2 and 4 data and tested on each visit individually

\begin{tabular}{|c|c|c|c|c|c|c|c|c|c|c|c|}
\hline \multirow[t]{2}{*}{ Actual } & \multicolumn{2}{|c|}{ Step 1} & \multicolumn{2}{|c|}{ Step 2} & \multicolumn{2}{|c|}{ Step 3} & \multicolumn{2}{|c|}{ Step 4} & \multicolumn{3}{|c|}{ Final call } \\
\hline & $\mathrm{NC}$ & $\mathrm{SZ}+\mathrm{BD}$ & NC & $\mathrm{SZ}$ & $\mathrm{NC}$ & $\mathrm{BD}$ & $\mathrm{SZ}$ & $\mathrm{BD}$ & $\mathrm{NC}$ & $\mathrm{SZ}$ & $\mathrm{BD}$ \\
\hline \multicolumn{12}{|c|}{ Training visit 2} \\
\hline $30 \mathrm{NC}$ & 30 & 0 & 24 & 6 & 26 & 4 & & & 21 & 5 & 4 \\
\hline $30 \mathrm{SZ}$ & 3 & 27 & 1 & 29 & & & 29 & 1 & 3 & 26 & 1 \\
\hline $30 \mathrm{BD}$ & 1 & 29 & & & 1 & 29 & 1 & 29 & 1 & 1 & 28 \\
\hline \multicolumn{12}{|c|}{ Testing visit 4} \\
\hline $30 \mathrm{NC}$ & 28 & 2 & 23 & 7 & 28 & 2 & & & 22 & 6 & 2 \\
\hline $30 \mathrm{SZ}$ & 1 & 29 & 0 & 30 & & & 29 & 1 & 1 & 28 & 1 \\
\hline $30 \mathrm{BD}$ & 1 & 29 & & & 0 & 30 & 0 & 30 & 1 & 0 & 29 \\
\hline
\end{tabular}

The confusion matrices show the numbers of subjects correctly and incorrectly classified for each iteration of the classification. Step 1: 11 genes diagnostically differentiating BD + SZ from NC. Step 2: 5 genes diagnostically differentiating SZ from NC. Step 3: 4 genes diagnostically differentiating BD from NC. Step 4: 3 genes diagnostically differentiating SZ from BD. Final call: summary of the step 1, 2, 3, and 4 classifications. BD, bipolar disorder; SZ, schizophrenia; NC, normal control.

Table 3. The overall results show a stable clinical biomarker signature of mRNA expression across a 90-day testretesting period with an accuracy of $88 \%$ on the retesting data

\begin{tabular}{|c|c|c|c|c|c|c|c|c|c|}
\hline \multirow[t]{2}{*}{ Predicted } & \multicolumn{3}{|c|}{ Visit 2 actual } & \multicolumn{3}{|c|}{ Visit 4 actual } & \multicolumn{3}{|c|}{ Both actual } \\
\hline & $\mathrm{BD}$ & SZ & $\mathrm{NC}$ & $\mathrm{BD}$ & $\mathrm{SZ}$ & $\mathrm{NC}$ & $\mathrm{BD}$ & $\mathrm{SZ}$ & $\mathrm{NC}$ \\
\hline $\mathrm{BD}$ & 28 & 1 & 4 & 29 & 1 & 2 & 57 & 2 & 6 \\
\hline SZ & 1 & 26 & 5 & 0 & 28 & 6 & 1 & 54 & 11 \\
\hline NC & 1 & 3 & 21 & 1 & 1 & 22 & 2 & 4 & 43 \\
\hline Accuracy & \multicolumn{3}{|c|}{$83 \%$} & \multicolumn{3}{|c|}{$88 \%$} & \multicolumn{3}{|c|}{$86 \%$} \\
\hline Sensitivity (SZ) & \multicolumn{3}{|c|}{$87 \%$} & \multicolumn{3}{|c|}{$93 \%$} & \multicolumn{3}{|c|}{$90 \%$} \\
\hline Sensitivity (BP) & \multicolumn{3}{|c|}{$93 \%$} & \multicolumn{3}{|c|}{$97 \%$} & \multicolumn{3}{|c|}{$95 \%$} \\
\hline Specificity (NC) & \multicolumn{3}{|c|}{$70 \%$} & \multicolumn{3}{|c|}{$73 \%$} & \multicolumn{3}{|c|}{$72 \%$} \\
\hline
\end{tabular}

BD, bipolar disorder; SZ, schizophrenia; NC, normal control.

significant ANOVA $p$ values for SZ compared to NC and represented fold changes greater than 1.25. We initially selected qPCR to validate the exon array findings and later, after completing the entire biomarker panel analysis, used NanoString (see below) for validation. Standard SYBR Green qPCR methods previously described by the Functional Genomics Laboratory (University of California, Irvine) were used to confirm gene expression values derived from the exon array data set [31]. Briefly, in developing SYBR Green assays we use exon junction-crossing primers to eliminate any genomic DNA from amplification. We assess primers for amplification consistency by single dissociation peaks to represent a single region of cDNA amplification, and minimal primer-dimer formation that could interfere with the amplification signal. We require the primers to amplify genes in our samples at fewer than 35 cycles to be usable. We also run samples in triplicate, and use two housekeeping genes (SDHA and HPRT1) that have Ct within similar ranges to those of the genes being assayed.

Exon Array Biomarkers for the

Differential Diagnosis of SZ and BD

\section{NanoString Gene Expression Platform}

A non-PCR-based approach to measuring RNA as a technical validation of the findings was used based upon NanoString technology, i.e., the nCounter ${ }^{\circledR}$ System (NanoString, Seattle, WA, USA) [68]. The NanoString platform requires a small quantity of RNA and provides digital counts of hybridization of mRNA to targets. The NanoString multiplex assay uses $100 \mathrm{ng}$ of total RNA, and all of the RNA samples were processed at the UCI Genomics HighThroughput Facility. We selected a total of 44 custom NanoString probes designed to match the closest probeset on the Affymetrix exon array that was in the biomarker panel, and 6 NanoString probes for housekeeping genes (online suppl. Table 2). The resulting NanoString data were processed according to the manufacturer's suggested protocol as outlined (NanoString Technologies, 2008-2012 \#127). Each data point was preprocessed by the 6 positive controls (PC), the 8 negative controls (NC), and the 5 housekeeping $(\mathrm{HK})$ genes as follows: 
Table 4. The overall results fitting a "leave-one-out" validation model to the remaining subjects show a stable clinical biomarker signature of mRNA expression across a 90-day test-retesting period with an accuracy greater than $87 \%$ for the retesting data at each of the model classification steps

\begin{tabular}{lclll}
\hline & $\begin{array}{l}\text { BD + SZ } \\
\text { vs. NC } \\
\text { (11-gene } \\
\text { panel) }\end{array}$ & $\begin{array}{l}\text { SZ vs. } \\
\text { NC } \\
\text { (5-gene } \\
\text { panel) }\end{array}$ & $\begin{array}{l}\text { BD vs. } \\
\text { NC } \\
\text { (4-gene } \\
\text { panel) }\end{array}$ & $\begin{array}{l}\text { SZ vs. } \\
\text { BD } \\
\text { (3-gene } \\
\text { panel) }\end{array}$ \\
\hline $\begin{array}{l}\text { Actual visit 2 data } \\
\text { Sensitivity (SZ) }\end{array}$ & & & & \\
$\begin{array}{l}\text { Sensitivity (BP) } \\
\text { Specificity (NC) }\end{array}$ & $93 \%$ & $97 \%$ & - & $97 \%$ \\
Accuracy & $100 \%$ & $80 \%$ & $87 \%$ & - \\
\hline "Leave-one-out" cross-validation & & & $97 \%$ \\
Sensitivity (SZ) & $90 \%$ & $93 \%$ & - & $90 \%$ \\
$\begin{array}{l}\text { Sensitivity (BP) } \\
\text { Specificity (NC) }\end{array}$ & $83 \%$ & $80 \%$ & $80 \%$ & - \\
Accuracy & $88 \%$ & $87 \%$ & $87 \%$ & $92 \%$ \\
\hline
\end{tabular}

BD, bipolar disorder; SZ, schizophrenia; NC, normal control.

Calculate for each subject/visit, the $\Sigma_{1}^{6} P C$ (sum of the positive controls), the $\bar{X}_{N C}$ (mean of the negative controls), and the $\sum_{1}^{5} H K$ (sum of the housekeeping genes).

Calculate across all subjects/visits, the $\bar{X}_{P C}=$ Sample $n_{1,180}\left(\Sigma_{1}^{6}\right.$ $P C) / 180$ (mean of the positive control sums), and the $\bar{X}_{H K}=$ Sample $n_{1,180}\left(\sum_{1}^{5} H K\right) / 180$ (mean of the housekeeping gene sums).

To normalize the gene expression data point (GEDP) for each subject/visit,

Normalized GEDP $=\left(G E D P \times\left(\sum_{1}^{6} P C / \bar{X}_{P C}\right)-(\bar{X}(N C))\right) /\left(\frac{\sum_{1}^{5} H K}{\bar{X}_{H K}}\right)$

that is, multiply GEDP by (sum of positive controls/mean of positive control sums), subtract the mean of the negative controls, and divide by (sum of housekeeping genes/mean of housekeeping gene sums). If the normalized GEDP was negative, it was set to 0 . The normalized GEDPs for the NanoString data were then analyzed for diagnostic accuracy using a model fitting approach. A potential gene probeset was selected by including all probesets that had $p<$ 0.1 in a univariate logistic regression fit of the probeset on at least one of the diagnosis comparisons ( $\mathrm{NC}$ vs. [SZ + BD], NC vs. SZ, $\mathrm{NC}$ vs. $\mathrm{BD}, \mathrm{SZ}$ vs. $\mathrm{BD}$ ) for the visit 2 data. The nominal $p$ value selected was based upon prior significance in the exon array.

\section{Results}

The top 300 probesets from the Affymetrix exon microarray based upon ANOVA significance (online suppl. Table 3) were evaluated for biomarker signature (as described in Methods) for differentiating BD, SZ, and NC subjects. The resulting biomarker signature was com-
Table 5. The diagnostic algorithm uses four individual steps, shown in each column

\begin{tabular}{llll}
\hline $\begin{array}{l}\text { BD + SZ vs. NC } \\
(11 \text {-gene panel })\end{array}$ & $\begin{array}{l}\text { SZ vs. NC } \\
(5 \text {-gene panel })\end{array}$ & $\begin{array}{l}\text { BD vs. NC } \\
(4 \text {-gene panel })\end{array}$ & $\begin{array}{l}\text { SZ vs. BD } \\
(3-\text { gene panel })\end{array}$ \\
\hline $\begin{array}{l}\text { AUC }=0.994 \\
(p<0.0001)\end{array}$ & $\begin{array}{l}\text { AUC }=0.954 \\
(p<0.0001)\end{array}$ & $\begin{array}{l}\text { AUC }=0.974 \\
(p<0.0001)\end{array}$ & $\begin{array}{l}\text { AUC }=0.998 \\
(p<0.0001)\end{array}$ \\
\hline
\end{tabular}

BD, bipolar disorder; SZ, schizophrenia; NC, normal control.

posed of 23 probesets that condensed into 18 known RefSeq genes (biomarker panel; Table 1). The diagnostic logistic model was built in four steps, using the visit 2 transcripts shown in Table 1.

The resulting logistic predictive model based on visit 2 was then applied to the visit 4 data. The summary of individual steps in the construction of the biomarker gene panels is shown in Table 2. The diagnostic algorithm uses a four-step decision model: step 1, BD and SZ versus NC; step 2, SZ versus NC; step 3, BD versus NC; and step 4, SZ versus $\mathrm{BD}$.

The 18-gene biomarker panels, using logistic regression modeling, correctly differentiated the three groups of subjects (SZ, BD type I, and NC) with high accuracy at visit 2 and visit 4 . The visit 2 cut-point probabilities for the SZ-NC comparison were significantly correlated with the visit 4 cut-point probabilities $(p<0.0001)$ with $r=0.74$ (95\% CI 0.59-0.83) showing temporal stability (Table 3 ).

The initial model was developed for selecting stable probesets across visits and incorporated all subjects and visits to select the most informative probesets. To test that no single subject was overly influential in determining the model, the initial probesets were evaluated by a "leaveone-out" method, whereby a new model is fit to the remaining subjects, and the left-out subject is identified. "Leave-one-out" cross-validation is a model validation technique for assessing how the results of a statistical analysis will generalize to an independent data set. It is mainly used in settings where the goal is prediction to estimate how accurately a predictive model will perform in practice. This cross-validation was applied to the visit 2 data from each of the four probeset panels (Table 4). The results are very consistent with the actual data, and the "leave-one-out" analyses indicate that the models should be predictive when applied to independent data cohorts.

The AUC for each step was greater than 0.95 , which is an indication of the high combined sensitivity and specificity of the classification into three groups (Table 5). When analyzing the same 18-gene biomarker panel and 
Table 6. The 18-gene signature was extracted from an independent data set of gene expression data and analyzed by the same logistic regression equations as derived from the fit to our original data

\begin{tabular}{llclrl}
\hline Subjects & NC, $n$ & SZ, $n$ & ROC AUC & Sensitivity & Specificity \\
\hline Antipsychotic free (all subjects) & 22 & 15 & 0.642 & $80.00 \%$ & $59.10 \%$ \\
Antipsychotic free (subjects aged $<30$ years) & 14 & 8 & 0.866 & $100.00 \%$ & $71.40 \%$ \\
\hline
\end{tabular}

Using this data set from antipsychotic-free SZ subjects, the 18-gene diagnostics produced a ROC accuracy of 0.866 in medication-free patients below 30 years of age. The classification of antipsychotic-free patients with SZ was made using data from the Illumina HT-8 array [6]. SZ, schizophrenia; NC, normal control.

including the white blood cell counts as a covariate, the analysis slightly improved the diagnostic predictability of SZ versus NC, and of BP and SZ versus NC (data not shown). The data were not normalized to blood counts (CBC measurements) for our main data analysis reported in this paper, but this model confirmed that potential differences in white blood cell counts did not change our results as reported.

To account for potential medication effects (since many of the SZ and BD subjects were on stable dosages of antipsychotic or mood stabilizer medications at the time of blood draw), we analyzed the possibility that these medications could drive some of the differential transcription signatures. A subset of unmedicated BD $(n=3)$ and SZ $(n=1)$ cases were analyzed using the 18gene diagnostics, which produced $100 \%$ accuracy in these 4 cases.

In addition, to test this possible explanation for the gene signature, we reanalyzed an even larger cohort of antipsychotic-free SZ patients using the Illumina gene expression microarray data sets [6]. The genome-wide RNA expression profiling was obtained with the Illumina HumanRef- 8 V 3 arrays for batch 1 and HumanRef-12 V3 arrays for batch 2 using Illumina's standard protocol at the Illumina facility of the University of California, Los Angeles. The raw microarray data were available at gene expression omnibus (GEO) under accession No. GSE38485. Data set 1 includes antipsychotic-free SZ patients $(n=15)$ and healthy controls $(n=22)$. The 18-gene signature was extracted from the Illumina data set and analyzed by the same logistic regression equations as derived from the fit to our original data. Using this independent Illumina data set of gene expression data from the antipsychotic-free SZ subjects, the 18-gene diagnostics produced a ROC accuracy of 0.866 in medication-free patients below 30 years of age (Table 6). These results were achieved with different gene expression technologies, different blood collection tubes, and different mRNA ex-
Table 7. qPCR results for candidate gene expression differences between $\mathrm{SZ}$ and NC

\begin{tabular}{|c|c|c|c|c|c|}
\hline $\begin{array}{l}\text { Exon array } \\
\text { (gene } \\
\text { symbol) }\end{array}$ & $\begin{array}{l}p \text { value } \\
\text { (SZ vs. } \\
\mathrm{NC} \text { ) }\end{array}$ & $\begin{array}{l}\text { Ratio } \\
\text { (SZ vs. } \\
\text { NC) }\end{array}$ & qPCR & $\begin{array}{l}p \text { value } \\
\text { (SZ vs. } \\
\text { NC) }\end{array}$ & $\begin{array}{l}\text { Ratio } \\
\text { (SZ vs. } \\
\text { NC) }\end{array}$ \\
\hline EDIL3 & $1.04 \mathrm{E}-13$ & 0.446 & EDIL3 & 0.01418 & 0.425 \\
\hline NRCAM & $1.37 \mathrm{E}-02$ & 0.525 & NRCAM & 0.06127 & 0.663 \\
\hline PTGDS & $1.41 \mathrm{E}-14$ & 0.722 & PTGDS & 0.04731 & 0.695 \\
\hline DSC2 & $6.86 \mathrm{E}-04$ & 1.592 & DSC2 & 0.00005 & 2.021 \\
\hline NRG1 & $1.14 \mathrm{E}-02$ & 2.062 & NRG1 & 0.01021 & 1.979 \\
\hline ITGA2B & $3.71 \mathrm{E}-02$ & 2.088 & ITGA2B & 0.00007 & 2.269 \\
\hline ITGB3 & $2.65 \mathrm{E}-02$ & 2.601 & ITGB3 & 0.00005 & 2.065 \\
\hline
\end{tabular}

qPCR, quantitative PCR; SZ, schizophrenia; NC, normal control.

traction techniques. The details on the methods and analysis of the antipsychotic-free patients are in the online supplementary Appendix. The duration of illness might allow us to test for more trait effects than state effects in the data set instead of using an arbitrary age cutoff for young subjects of below 30 years. Duration of illness is not entirely accurate, due to retrospective subject recall, which is why we chose age as our cut-point. Age and duration of illness are significantly collinear for $\mathrm{BD}$ subjects $(r=0.65 ; p<0.001)$ and for SZ subjects $(r=0.62 ; p<$ $0.001)$. Further, we did not have access to the Illumina duration of illness data for comparison.

\section{qPCR Validation of the Exon Array}

The transcripts were validated for $\mathrm{SZ}$ and $\mathrm{NC}$ using the qPCR methods described by Morgan et al. [31]. The transcripts for qPCR were selected based upon the differential expression results from the SZ-NC comparisons and upon visual inspection of exon expression differences across probesets that map to RefSeq transcripts. The qPCR results showed concordance $(r=0.86)$ between 
Table 8. The NanoString data set was analyzed by ANOVA, and the following 23 probesets representing 11 genes passed the initial ANOVA filter $(p<0.1)$

$\begin{array}{llll}\text { 2537112_SH3YL1 (30) } & \text { 3554838_CRIP2 (39) } & \text { 2661997_OXTR (43) } & \text { 2723770_TBC1D1 (55) } \\ \text { 2537128_SH3YL1 (61) } & \text { 3554839_CRIP2 (58) } & \text { 2906726_TREML4 (45) } & \text { 4048243_HLA-DRB5 (57) } \\ \text { 2647127_CPA3 (35) } & \text { 3554833_CRIP2 (68) } & \text { 2906736_TREML4 (50) } & \text { 3195045_PTGDS (59) } \\ \text { 2647122_CPA3 (47) } & 2418615 \text { SLC44A5 (40) } & \text { 2906735_TREML4 (53) } & \text { 2401364_TCEA3 (64) } \\ \text { 2647124_CPA3 (65) } & \text { 2418581_SLC44A5 (46) } & \text { 2906733_TREML4 (62) } & \text { 2401362_TCEA3 (70) } \\ \text { 2647119_CPA3 (69) } & \text { 2418590_SLC44A5 (51) } & \text { 3063538_TRIM4 (52) } & \end{array}$

The format is: “Affymetrix Exon Array Probeset ID_Gene Symbol (variable number entered into regression).”

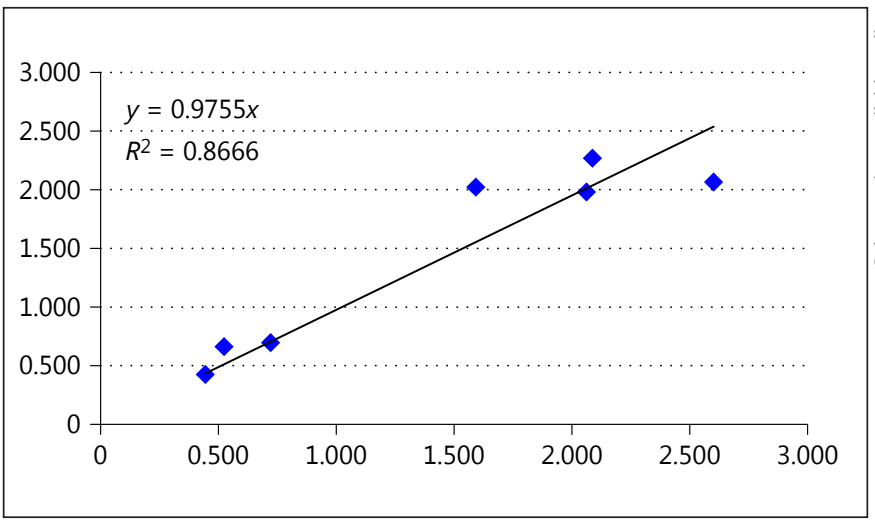

Fig. 2. The fold change ratio (SZ compared to NC) for the exon microarray results was compared to the fold change ratio (SZ compared to NC) of quantitative PCR. The fold changes were highly correlated. SZ, schizophrenia; NC, normal control.

exon array expression differences and qPCR (Table 7; Fig. 2). We used NanoString to test the complete panel of 18 biomarker genes.

\section{NanoString Platform Accuracy for Diagnostic}

\section{Classification}

The NanoString platform was chosen to validate the biomarker panel using the entire panel as well as probesets mapping close to the original exon array probesets. With the NanoString data, the best multivariate logistic regression model for diagnosis at visit 2 was obtained by stepwise backward elimination from the full 23-probeset multivariate model to a reduced model with all included probesets significant at $p<0.05$ or $p<0.1$ to maintain an AUC above 0.9 (Table 8).

A cut-point for each reduced diagnostic model was found which optimized both sensitivity and specificity based on the visit 2 data, which reduced the useful probeset number to 12 (Table 9). The diagnostic model and
Table 9. Summary of NanoString cut-point diagnostic accuracy

\begin{tabular}{|c|c|c|c|c|}
\hline Significant probesets ${ }^{1}$ & $\begin{array}{l}\text { NC vs. } \\
\text { SZ/BD }\end{array}$ & $\begin{array}{l}\text { NC vs. } \\
\text { SZ }\end{array}$ & $\begin{array}{l}\text { NC vs. } \\
\text { BD }\end{array}$ & $\begin{array}{l}\mathrm{SZ} \text { vs. } \\
\mathrm{BD}\end{array}$ \\
\hline 2537112_SH3YL1 (30) & $\mathrm{x}$ & $\mathrm{x}$ & $\mathrm{x}$ & $\mathrm{x}$ \\
\hline 2537128_SH3YL1 (61) & & $\mathrm{x}$ & $\mathrm{x}$ & $\mathrm{x}$ \\
\hline 2647124_CPA3 (65) & $\mathrm{x}$ & $\mathrm{x}$ & $\mathrm{x}$ & $\mathrm{x}$ \\
\hline 2647119_CPA3 (69) & $\mathrm{x}$ & $\mathrm{x}$ & $\mathrm{x}$ & $\mathrm{x}$ \\
\hline 3554833_CRIP2 (68) & $\mathrm{x}$ & & $\mathrm{x}$ & \\
\hline 2418590_SLC44A5 (51) & $\mathrm{x}$ & $\mathrm{x}$ & & \\
\hline 2661997_OXTR (43) & & & $\mathrm{x}$ & $\mathrm{x}$ \\
\hline 2906733_TREML4 (62) & & $\mathrm{x}$ & & \\
\hline 3063538_TRIM4 (52) & $\mathrm{x}$ & $\mathrm{x}$ & $\mathrm{x}$ & \\
\hline 2723770_TBC1D1 (55) & & & & $\mathrm{x}$ \\
\hline 3195045_PTGDS (59) & $\mathrm{X}$ & $\mathrm{x}$ & $\mathrm{x}$ & $\mathrm{x}$ \\
\hline 2401362_TCEA3 (70) & & & & $\mathrm{x}$ \\
\hline AUC & 0.913 & 0.990 & 0.953 & 0.905 \\
\hline Visit 2 sensitivity & $98.3 \%$ & $96.6 \%$ & $89.3 \%$ & $86.2 \%$ \\
\hline Visit 2 specificity & $75.0 \%$ & $96.4 \%$ & $92.9 \%$ & $82.1 \%$ \\
\hline Visit 4 sensitivity & $87.5 \%$ & $75.0 \%$ & $75.0 \%$ & $57.1 \%$ \\
\hline Visit 4 specificity & $60.0 \%$ & $80.0 \%$ & $76.0 \%$ & $85.7 \%$ \\
\hline Visit 2/4 agreement & $77.6 \%$ & $76.0 \%$ & $75.5 \%$ & $64.2 \%$ \\
\hline
\end{tabular}

BD, bipolar disorder; SZ, schizophrenia; NC, normal control. ${ }^{1}$ Format as explained in Table 8.

cut-point were then applied to the visit 4 data to estimate the visit 4 sensitivity and specificity as well as the agreement between the visit 2 and the visit 4 diagnostic predictions.

\section{Comparison of Affymetrix Exon Array with \\ NanoString Results}

The prediction accuracies for diagnosis were compared between the Affymetrix exon array and the NanoString platform. In general, for the exon array, the model performed equally well for visit 2 and visit 4 data due to the data driving the selection algorithm from the original platform. The visit 2 /visit 4 agreement for the Af- 
Table 10. Comparison of Affymetrix and NanoString results showing that the Affymetrix exon array had higher sensitivity and specificity for prediction

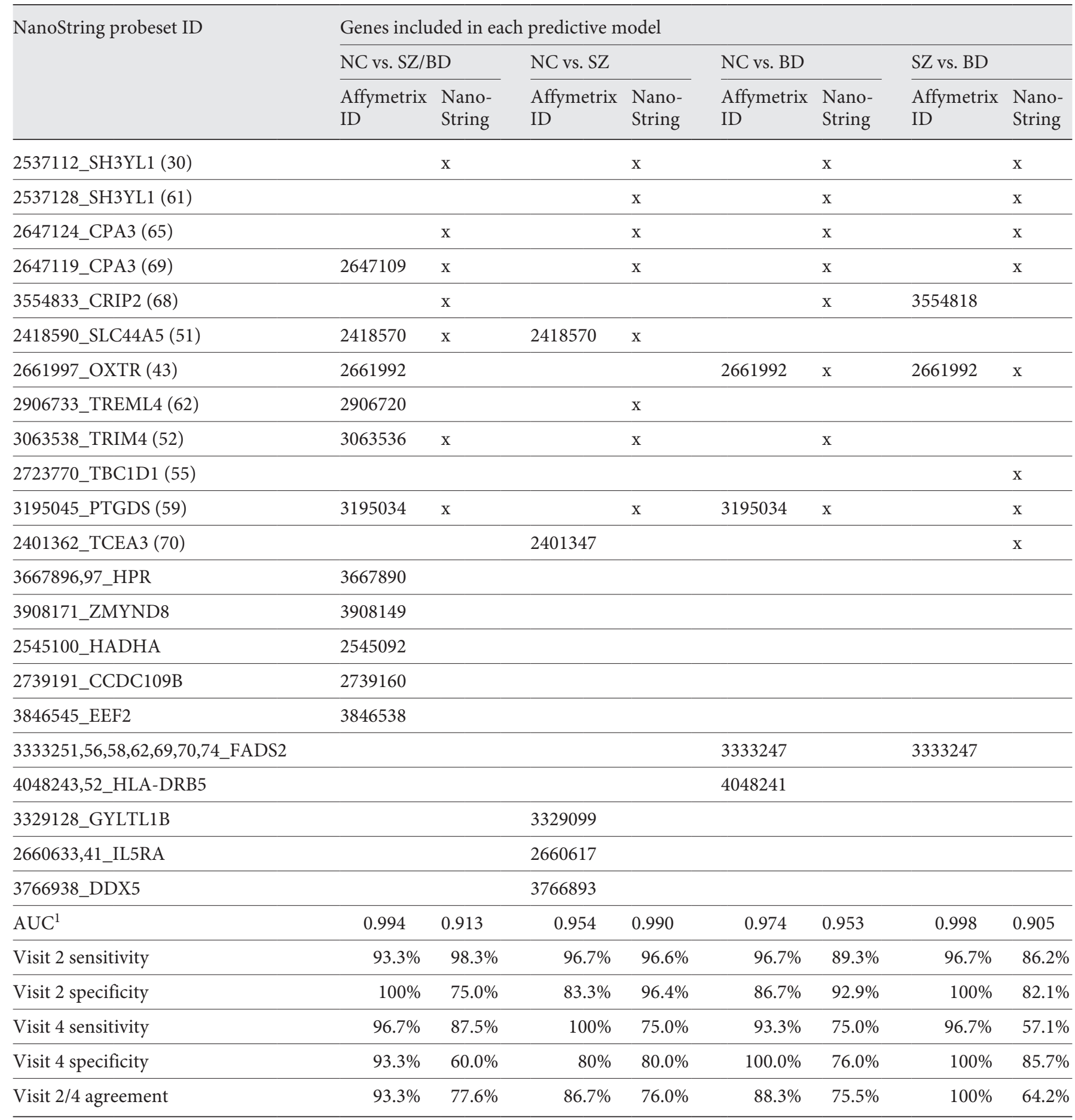

BD, bipolar disorder; SZ, schizophrenia; NC, normal control. ${ }^{1}$ The AUC was for combined visit 2 and 4 modeling, and each visit was evaluated for predictions individually.

Exon Array Biomarkers for the

Differential Diagnosis of SZ and BD 
Table 11. Overlap between a mega-analysis of dysregulated genes in blood [35] and the current study

\begin{tabular}{|c|c|c|c|c|c|c|}
\hline FAM118A & family with sequence similarity 118 , member A & -0.37 & $5.90 \mathrm{E}-04$ & FAM118A & $4.17 \mathrm{E}-13$ & 0.58 \\
\hline MRPL42 & mitochondrial ribosomal protein L42 & 0.27 & $1.90 \mathrm{E}-02$ & MRPL42 & 0.000535 & 1.24 \\
\hline PHF14 & PHD finger protein 14 & 0.26 & $2.50 \mathrm{E}-02$ & PHF14 & $3.09 \mathrm{E}-14$ & 0.49 \\
\hline PHIP & $\begin{array}{l}\text { pleckstrin homology domain } \\
\text { interacting protein }\end{array}$ & 0.29 & $9.10 \mathrm{E}-03$ & PHIP & $4.66 \mathrm{E}-29$ & 0.59 \\
\hline SLC22A4 & $\begin{array}{l}\text { solute carrier family } 22 \text { (organic cation/ } \\
\text { zwitterion transporter), member } 4\end{array}$ & 0.34 & $3.30 \mathrm{E}-03$ & SLC22A4 & 0.039619 & 1.14 \\
\hline STX2 & syntaxin 2 & 0.28 & $1.30 \mathrm{E}-02$ & STX2 & $1.49 \mathrm{E}-05$ & 0.81 \\
\hline TFB1M & transcription factor B1, mitochondrial & -0.5 & $3.60 \mathrm{E}-02$ & TFB1M & $1.11 \mathrm{E}-05$ & 0.79 \\
\hline TNFRSF21 & $\begin{array}{l}\text { tumor necrosis factor receptor } \\
\text { superfamily, member } 21\end{array}$ & -0.31 & $3.70 \mathrm{E}-03$ & TNFRSF21 & $1.96 \mathrm{E}-13$ & 0.53 \\
\hline
\end{tabular}

FDR, false discovery rate; SZ, schizophrenia; NC, normal control.

fymetrix exon array was significantly higher than for the NanoString reproducibility diagnosis classification (twotailed paired $t$ test, $p=0.046$ ). These results show that the test-retest reproducibility of the algorithm using the same subjects was best when using the original platform (Table $10)$, although there was general agreement across platforms.

In comparing the qPCR, exon array, and NanoString results, 5 of 7 genes tested by qPCR passed with significant $p$ values, while all genes were concordant with fold changes between the exon array and qPCR results. The biomarker panel was developed more than 2 years after the initial qPCR approach to validate the findings on the exon array. Therefore, only 7 genes were selected by qPCR for confirmation of the exon array findings. Instead of qPCR, the panel of NanoString markers was used for validation of the panel of biomarkers. The NanoString data set confirmed that the best prediction was based upon 10 NanoString genes of the original 18 exon array genes.

\section{Bioinformatic Analysis of the Biomarker Panel}

A recent mega-analysis of differentially expressed genes in SZ across 9 studies was conducted in bloodbased transcriptomics [35]. There were 1,624 genes that survived the FDR that were compared to the top 122 genes identified by ANOVA in the present study. The formula for the expected number of genes was calculated as:

$$
\begin{aligned}
& \text { Expected gene number overlaps }\left[\left(p_{1} p_{2}\right) \times 24,000\right] \\
& =\text { where } p_{1} \text { is } \frac{\text { observed genes in list } 1}{24,000} \text { and } p_{2} \text { is } \frac{\text { observed genes in list } 2}{24,000} .
\end{aligned}
$$

This formula yields an expected number of 8.2 genes, while the actually observed number was 9 genes; we conclude that the overlap was not exceeding chance level. Interestingly, 2 mitochondrial genes were found among these top 9, and they agreed in fold change direction across the two studies (Table 11): (1) mitochondrial ribosomal protein L42 (MRPL42) and (2) transcription factor B1, mitochondrial (TFB1M).

Regarding genes implicated in $\mathrm{BD}$ or SZ from a database of genome-wide association study (GWAS)-curated genes (GWASdb v2 [69]) there were 2,189 unique genes meeting this criterion $(p<0.001)$. In our list of 122 differentially expressed genes for BD and SZ that were temporally stable, there was an overlap of 22 genes with the GWASdb genes (Table 12), resulting in a 2 -fold enrichment, as only 11 genes were expected ( $p=0.029$, onetailed Pearson).

An IPA (Ingenuity Pathway Analysis) of the top 122 genes for the BD and SZ biomarker panel showed some overlap in a network related to 2 different proto-oncogenes: (1) REL and (2) MKL2. The REL gene (REL protooncogene, NF- $\kappa \mathrm{B}$ subunit) encodes a protein that belongs to the Rel homology domain/immunoglobulin-like fold, plexin, transcription factor (RHD/IPT) family. This protooncogene plays a role in the survival and proliferation of $\mathrm{B}$ lymphocytes. SNPs in this gene are associated with susceptibility to ulcerative colitis and rheumatoid arthritis. The direct REL gene targets were differentially expressed in $\mathrm{BD}$ and SZ (Fig. 3). Opposite fold change genes related to REL were seen in BD and SZ; for instance, ATP11A was upregulated in SZ (1.68) and downregulated in $\mathrm{BD}(-1.63)$, 
Table 12. Overlap between GWASdb v2 [69] and the current study of differentially expressed genes in BD and SZ

\begin{tabular}{ll}
\hline Overlap BD and GWASdb v2 & Overlap SZ and GWASdb v2 \\
\hline CNTNAP2 & CDC42BPB \\
TBC1D1 & KANK1 \\
EDIL3 & PRICKLE1 \\
LRRC16A & SLC44A5 \\
TCEA3 & FCER2 \\
NRCAM & AK5 \\
PAX5 & DSP \\
EXO1 & DNAH6 \\
JUP & CNTNAP2 \\
& C22Orf34 \\
& NPAS2 \\
& SUMF1 \\
& PAX5 \\
& LAPTM4B \\
& EXO1 \\
& LRRC16A \\
& ADARB2 \\
\hline
\end{tabular}

GWASdb contains lists of genes that have been associated with either or both disorders by GWAS. There was an enrichment of the overlap of genes found to be differentially expressed and associated with disorder. GWAS, genome-wide association study; BD, bipolar disorder; SZ, schizophrenia.

while an opposite relationship was seen for PHF14 (downregulated in SZ [-2.01] and upregulated in BD [2.95]).

MKL2 is a proto-oncogene which is widely distributed, highly expressed in brain regions such as the dentate gyrus (Allen Institute Brain Science [70]), and associated with microcephaly [71]. The MKL2 gene consists of multiple exons many of which are downregulated in SZ and not significantly changed in $\mathrm{BD}$. The exon levels in blood for MKL2 were differentially expressed in SZ, although not in the top 300 genes (Fig. 4). The downstream effects on MKL2-regulated genes in the top biomarker classification genes were in the expected directions, e.g., there were decreased fold changes seen in genes regulated by MKL2 in SZ (ACTA2, FADS2, and CPA3), while the same set was upregulated in BD.

Two additional genes in the biomarker panels, i.e., PTGDS (prostaglandin $\mathrm{D}_{2}\left[\mathrm{PGD}_{2}\right]$ synthase) and FADS2 (fatty acid desaturase 2), were also found to be candidate genes in the literature. PTGDS expression was reduced in BD PBMCs [72], also in the present study $(p=0.000271$; fold change -1.23), and it was down in SZ as well ( $p=$ 9.04E-12; fold change -1.52). In BD and SZ there appears to be a downregulation of PTGDS, which also was ranked

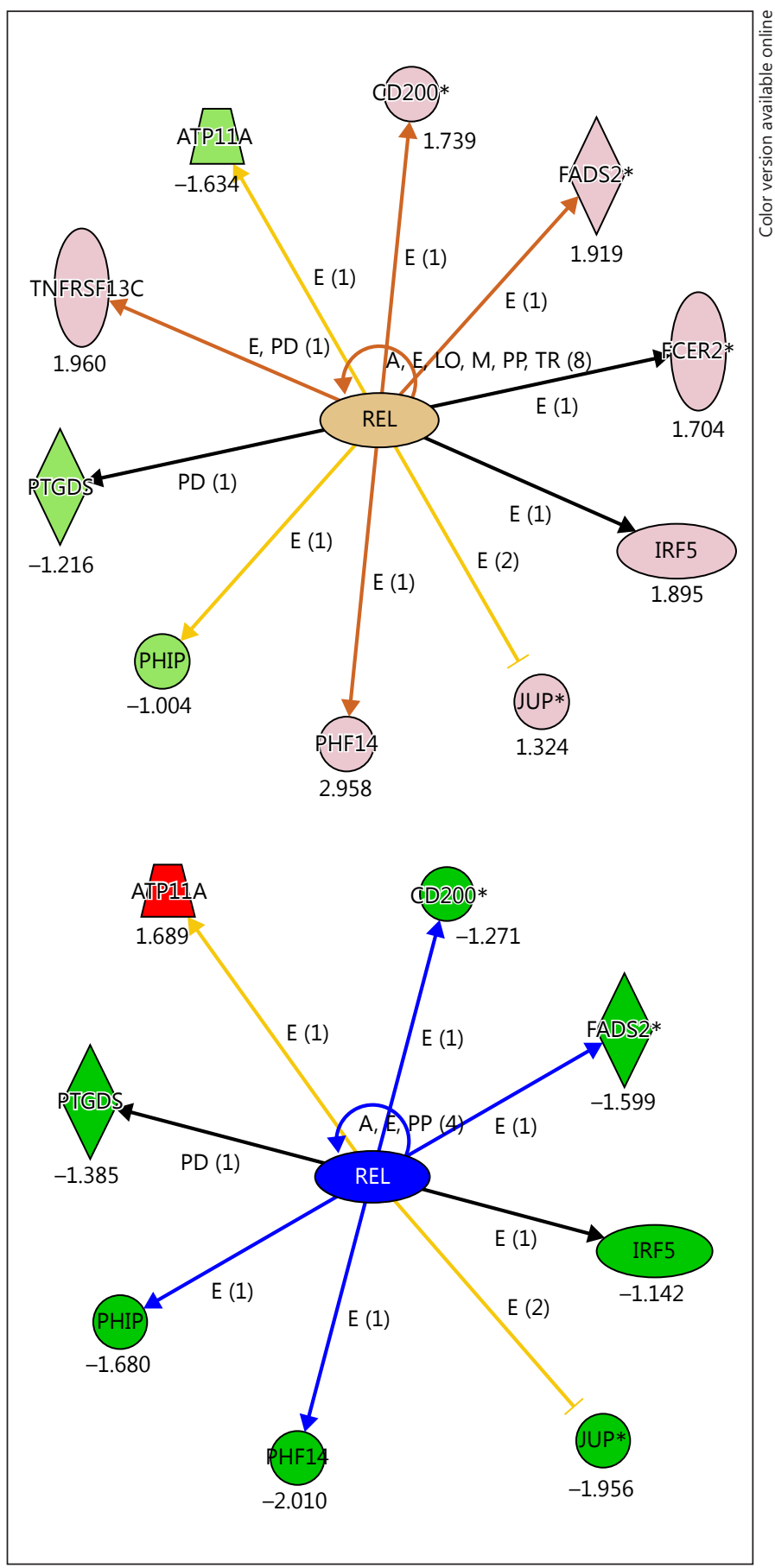

Fig. 3. The REL transcription factor is a central hub for genes in the top 122 differentially expressed list. The top panel shows the relationship for $\mathrm{BD}$ compared to $\mathrm{NC}$, the bottom panel shows the relationship for SZ compared to NC. Many of the genes are oppositely regulated across $\mathrm{BD}$ and $\mathrm{SZ}$. BD, bipolar disorder; SZ, schizophrenia; NC, normal control. 


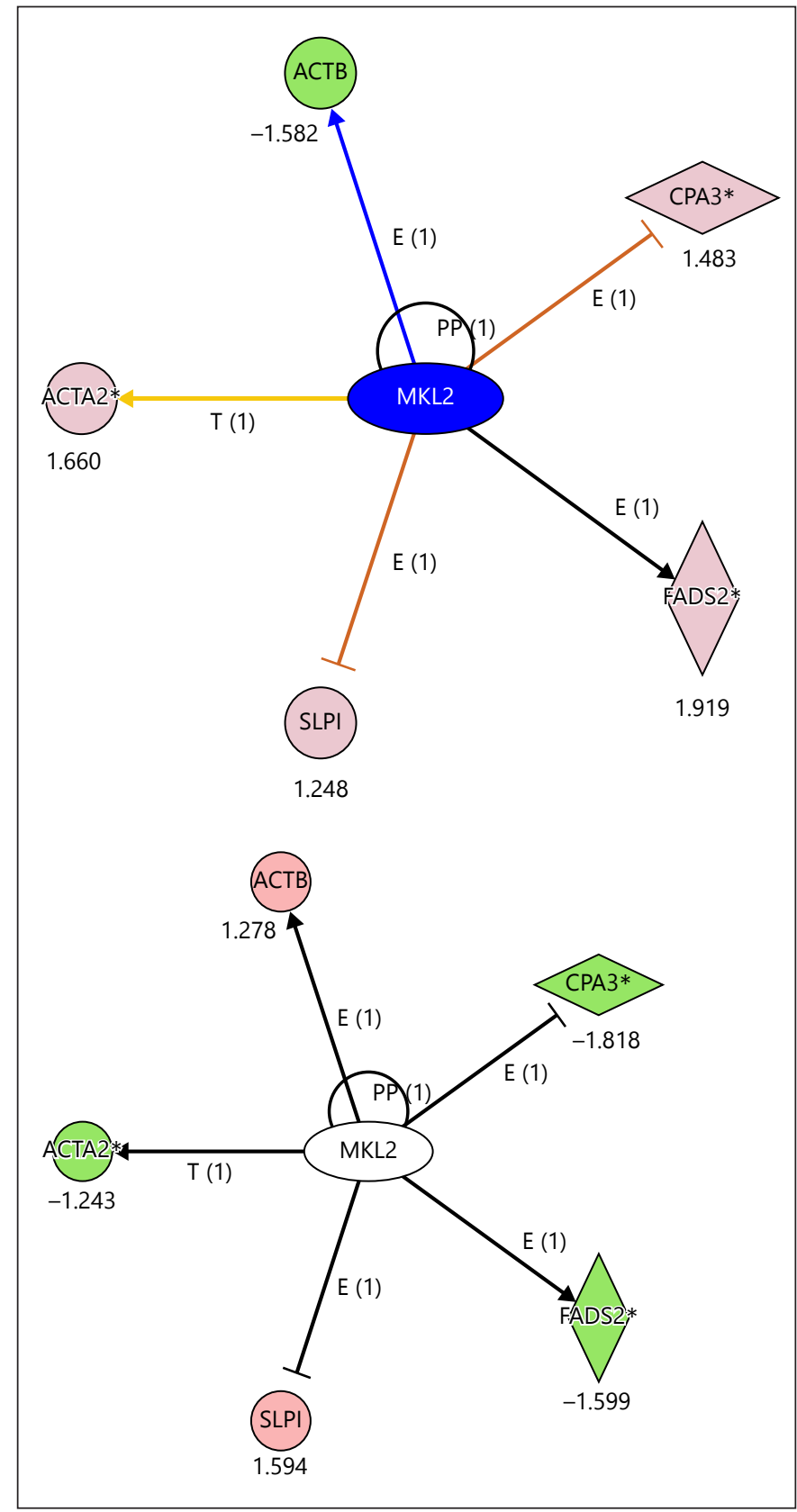

Fig. 4. The MKL2 proto-oncogene is a central hub for genes in the top 122 differentially expressed list. The top panel shows the relationship for BD compared to NC, the bottom panel shows the relationship for SZ compared to NC. Many of the genes are oppositely regulated across $\mathrm{BD}$ and $\mathrm{SZ}$. BD, bipolar disorder; $\mathrm{SZ}$, schizophrenia; NC, normal control.

high in the convergent functional genomics paradigm for anxiety [73]. FADS2 expression was decreased in SZ in this study ( $p=9.20 \mathrm{E}-09$; fold change -1.80$)$ and increased in $\mathrm{BD}(p=2.79 \mathrm{E}-06$; fold change 1.6$)$.
The FADS2 and PTGDS genes work in the biosynthesis of the fatty acid pathway and converge on key molecules in BD such as arachidonic acid. HADHA was significantly increased in BD ( $p=4.74 \mathrm{E}-08$; fold change $1.67)$ and was not changed in SZ. HADHA is closely related to FADS2 and HADHA in the fatty acid pathway (Fig. 5) and along with PTGDS participates in the biosynthesis and degradation of unsaturated fatty acids, an important pathway implicated in BD and SZ.

\section{Discussion}

To determine stable temporal biomarkers, this study evaluated whole blood gene expression at two different time points using the same subjects (SZ, BD, and $\mathrm{NC}$ ) for differential diagnosis. The diagnostic algorithm used logistic regression modeling and a total of 18 uniquely expressed exons within known mRNA transcripts. The model discriminated SZ and BD from each other, as well as both from healthy controls in four steps. The upper limit of accuracy achieved in this biomarker study was $88 \%$, using an independent visit of the same patients. When using the "leave-one-out" evaluation algorithm, the results were very consistent with the actual data; thus, the "leave-one-out" analyses indicated that the models were not driven by outliers and that they should be predictive when applied to independent data cohorts.

It is expected that the application of these panels to first-episode or prodromal subjects may improve prediction for those subjects that ultimately convert to either illness, as well as for the millions of patients worldwide that have not received any clear diagnosis of their ongoing disorder. This will require an additional validation study of the biomarker signatures with a larger cohort in a follow-on project.

The differences in expression of 3 genes (PTGDS, FADS2, and HADHA) related to polyunsaturated fatty acid (PUFA) and prostaglandin biosynthesis were used for the final biomarker panels to differentiate between SZ, $\mathrm{BD}$, and NC. Previously, these genes have been associated with psychiatric disorders such as $\mathrm{BD}$, major affective disorder, SZ, and anxiety. PTGDS is involved in the synthesis of $\mathrm{PGD}_{2}$ from $\mathrm{PGH}_{2}$, the cyclooxygenase-mediated product of arachidonic acid which is a PUFA [4]. PTGDS is a top anxiety gene modulated by changes in PUFA (omega-3 fatty acid docosahexaenoic acid) [73] on the convergent functional genomics scale. Increased expression of FADS2 has been found in SZ and BD brains post 
Fig. 5. Modified KEGG (Kyoto Encyclopedia of Genes and Genomes) pathway labels for FADS2 and HADHA participate in the conversion of polyunsaturated fatty acids and fatty acid $\beta$-oxidation.

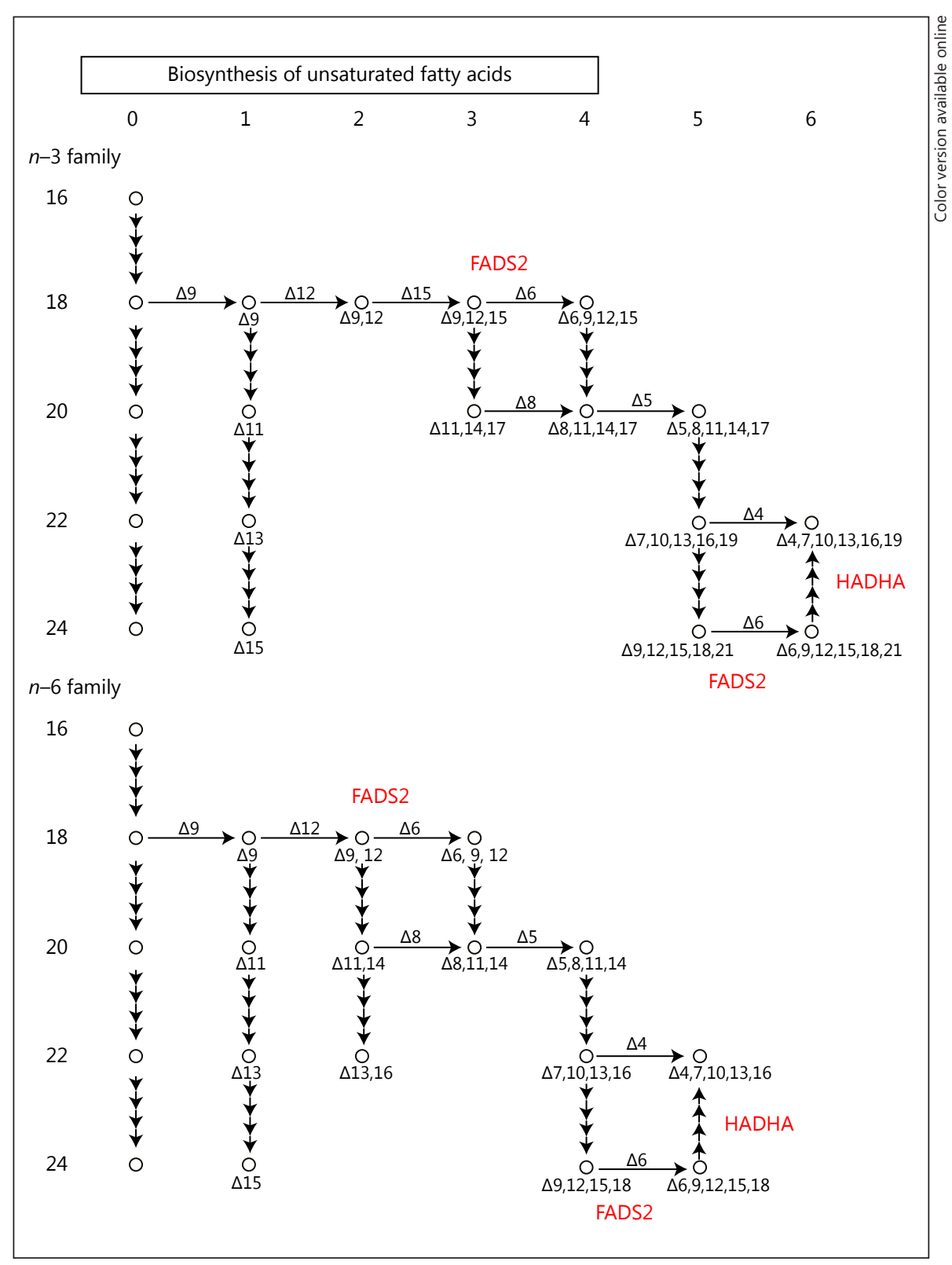

mortem $[74,75]$. FADS2 activity is increased in $\mathrm{BD}$ and is associated with suicidal behavior [76].

In the present study, we found an increased expression of FADS2 in BD, in agreement with the FADS2 findings reported. The increased activity of FADS2 could reduce PUFA levels of both arachidonic acid and eicosapentaenoic acid by promoting conversion to longer-chain fatty acids, shown in both the $n-3$ and the $n-6$ pathway (Fig. 5). Thus, PUFA supplementation with $n-3$ fatty acids in mood disorder was effective in reducing mood symptoms in 4 out of 7 well-controlled studies [76]. The expression data for FADS2, while interesting, could be subject to dietary influence, such as amounts and types of daily dietary intake of fatty acids, the timing of intake, and also medication effects on these genes. Further, genetics plays a significant role, especially in modulating levels of fatty acids and FADS2 expression. Another limitation to the assessment of these genes as representing actual pathophysiological markers is that, potentially, stress could modulate the biomarker panel genes. Many patients with $\mathrm{BD}$ and SZ experience higher levels of stress than controls, which might explain differences in immune cell activation and 
prostaglandin synthesis. We examined our biomarker panel of 18 genes in our unpublished stress data set ( $M$. Martin and M.P.V.) using the same exon array approach and Tempus tube approach on healthy volunteers who underwent sleep deprivation and 9 repeated blood draws over $54 \mathrm{~h}$, i.e., every $6 \mathrm{~h}$. We checked our results for the healthy controls and found that 4 transcripts that passed Bonferroni corrections were affected by time of day and, potentially, stress induction as well (DDX5, EEF2, HADHA, and CCDC109B). However, these 4 genes did not vary in the present study, even though in the stress data set these genes varied by time of day. Taken together, although these 4 genes were dysregulated as a consequence of time of day and sleep deprivation, these genes in the present study were stable across 8 weeks of time, and would have been expected to show some fluctuation with stress levels or time of day.

Several design points could be potential limitations as well. First, the study was not designed to test for treatment effects or treatment response. Although we have some psychiatric ratings available for the subjects, a feasible approach would be to identify treatment responders versus nonresponders using a within-subject design, comparing the severity of psychotic symptoms before and after 8 weeks of treatment, and correlating stably expressed biomarkers with response to treatment. This alternative approach would yield useful information, and is planned for a follow-on analysis of the data to explore biomarkers of treatment response. An inspection of the "treatment responders" in the study showed that the majority of patients did not change their medications, were clinically stable, and maintained similar psychiatric ratings across the 8 weeks. Further, for differentiating diseased from nondiseased groups, we adopted an outpatient case-control analysis. Another approach that could yield potential data in a future test of the biomarker panel is whether unaffected siblings of psychiatric patients could be reliably differentiated by the panel. This approach could be utilized as well in future studies. The current biomarker panel could also be used on subjects with major depressive disorder to examine if there is some coherence to a subclassification into more psychotic (in the SZ group) or more affective disordered (in the $\mathrm{BD}$ group) for aiding in potential treatments for these patients. These directions will go far in providing useful information to clinicians, researchers, and patients to guide our understanding of these illnesses.

A tremendous effort has been expended into GWAS of $\mathrm{SZ}$ [77] and BD [78], and it is recognized that there is a large number of common variants contributing to the polygenic susceptibility for these disorders. Estimates from several hundred genes of small effect size, as published in the largest international genetic study of SZ [79], to the possibility that thousands of genes are involved in the pathogenesis of SZ were made [80]. We have highlighted several genes that contribute towards this susceptibility using transcription analysis (Table 12), finding some overlap between GWAS variants and differential gene expression. Our present biomarker results overlap with a genetic database of genes implicated in either BD or SZ or both from a database of GWAS-curated genes (GWASdb v2 [69]). We found a significant overlap with our list of 122 differentially expressed genes for $\mathrm{BD}$ and SZ that were temporally stable (Table 12). The overlap of 22 genes suggests that peripheral biomarkers of either SZ or BD may have some genetic component that could drive differential expression. This leaves open the possibility that a number of serum proteins [81-85] and transcripts will advance as biomarkers.

Additionally, 2 upstream transcription factors merit further investigation, i.e., REL and MKL2, which appear to oppositely regulate genes in $\mathrm{BD}$ and SZ. The downstream targets of the genes were used to differentially diagnose subjects with BD and SZ. These proto-oncogenes have not previously been associated with psychiatric disorders. The expression of these 2 transcription factors (REL and MKL2) was studied in the cerebral cortex and shown to be expressed in microglia and endothelial cell types at higher levels than in neurons and astrocytes [86]. This raises the possibility that blood transcriptomics is mirroring some of the microglial/endothelial cell activity in the brain. It is known that peripheral cells can interact with brain microglia and endothelial cells.

There are prior reports supporting the directions of gene expression changes found in this biomarker study. For example, there was a consistent increase in expression of IL5RA (interleukin 5 receptor, alpha) in lithium-treated subjects with BD in PBMCs that passed a strict FDR [87]. In the final biomarker panel, we also found a trend for an increase in IL5RA expression in BD ( $p$ value for $\mathrm{BD}=0.056$; fold change 1.16); however, IL5RA expression in SZ was significantly decreased and passing the FDR ( $p$ value for SZ vs. NC $=2.65 \mathrm{E}-08$; fold change -1.59). Regarding PLB1 (phospholipase B1) in PBMCs, lithium decreased its expression ( -1.17 fold change), passing the FDR [87] in PBMCs, while in the present study, PLB1 was significantly decreased in BD by -1.19 and was not significantly increased in SZ ( $p=0.06$; fold change 1.16). It is unlikely that some expression in the biomarker panel might be due to lithium treatment, since only 2 BD subjects were lithium treated in this study. An- 
other ramification of using biomarkers is to provide a method for monitoring drug efficacy and other appropriate early psychosocial interventions for mental disorders. In a planned separate analysis, we will further correlate the phenotypic neuropsychiatric rating data obtained from each patient along with the gene expression data.

Over 100,000 adolescent Americans suffer from symptoms of psychosis each year, as well as millions of patients worldwide that have not received any clear differential diagnosis of their ongoing disorder; yet, currently, there are no biomarker tests that are FDA approved to classify $\mathrm{SZ}$ or BD. There is a serious need for "objective" clinical laboratory tests for an early diagnosis of these mental disorders, since today these disorders may typically take months or even years to reach a diagnosis and for patients to receive effective treatment. The lag in treatment is associated with an increase in suicide rates and recurrent episodes of psychosis and mood dysregulation. There is a large increase in deaths reported among first-episode psychotic subjects due to lack of treatment after the first year of illness [1]. Thus, it is important to have objective biomarkers to help implement treatment at an early stage. One estimate of the direct and indirect annual costs in the USA for SZ is USD 174 billion [88], with an additional cost of USD 151 billion for BD [89]. Biomarker signatures could lead to faster and more accurate diagnoses, reducing the duration of untreated psychosis, suicidality, and cognitive decline and adding to an understanding of the shared and unique pathophysiologies of each disorder. The blood test results that are described in this paper, if further validated in a larger number of subjects, will offer molecular diagnostic support for psychiatrists' clinical evaluation with rapid clinical laboratory test results.

\section{Acknowledgements}

The authors wish to thank Nancy J. Hollenbeck at the University of Iowa for subject recruitment and enrollment for this study.

\section{Statement of Ethics}

The University of Iowa and the Institutional Review Board approved the procedures in the study. The chronic SZ and BD type I outpatients aged 18-45 years provided consent for the study.

\section{Disclosure Statement}

A SBIR Phase I project "Gene expression exon array biomarkers to diagnose schizophrenia" (R43 MH090806) was awarded (T.W.O.) for developing a blood-based commercial biomarker test for psychiatric disorders. The authors (M.P.V. and T.W.O.) are officers of Laguna Diagnostic, LLC, and co-inventors of a patent application to commercialize the results presented.

\section{References}

1 Schoenbaum M, Sutherland JM, Chappel A, Azrin S, Goldstein AB, Rupp A, Heinssen RK: Twelve-month health care use and mortality in commercially insured young people with incident psychosis in the United States. Schizophr Bull 2017;43:1262-1272.

-2 Kebir O, Chaumette B, Rivollier F, Miozzo F, Lemieux Perreault LP, Barhdadi A, Provost S, Plaze M, Bourgin J; ICAAR Team, Gaillard R, et al: Methylomic changes during conversion to psychosis. Mol Psychiatry 2017;22:512-518.

-3 Schiavone S, Trabace L: Inflammation, stress response, and redox dysregulation biomarkers: clinical outcomes and pharmacological implications for psychosis. Front Psychiatry 2017;8:203.

4 Begemann M, Sargin D, Rossner MJ, Bartels C, Theis F, Wichert SP, Stender N, Fischer B, Sperling S, Stawicki S, et al: Episode-specific differential gene expression of peripheral blood mononuclear cells in rapid cycling supports novel treatment approaches. Mol Med 2008; 14:546-552.

-5 Bowden NA, Weidenhofer J, Scott RJ, Schall U, Todd J, Michie PT, Tooney PA: Preliminary investigation of gene expression pro- files in peripheral blood lymphocytes in schizophrenia. Schizophr Res 2006;82:175183.

6 de Jong S, Boks MP, Fuller TF, Strengman E, Janson E, de Kovel CG, Ori AP, Vi N, Mulder $\mathrm{F}$, Blom JD, et al: A gene co-expression network in whole blood of schizophrenia patients is independent of antipsychotic-use and enriched for brain-expressed genes. PLoS One 2012;7:e39498.

7 Glatt SJ, Everall IP, Kremen WS, Corbeil J, Sásik R, Khanlou N, Han M, Liew CC, Tsuang MT: Comparative gene expression analysis of blood and brain provides concurrent validation of SELENBP1 up-regulation in schizophrenia. Proc Natl Acad Sci USA 2005;102: 15533-15538.

8 Middleton FA, Pato CN, Gentile KL, McGann L, Brown AM, Trauzzi M, Diab H, Morley CP, Medeiros H, Macedo A, et al: Gene expression analysis of peripheral blood leukocytes from discordant sib-pairs with schizophrenia and bipolar disorder reveals points of convergence between genetic and functional genomic approaches. Am J Med Genet B Neuropsychiatr Genet 2005;136B:12-25.
9 Naydenov AV, MacDonald ML, Ongur D, Konradi C: Differences in lymphocyte electron transport gene expression levels between subjects with bipolar disorder and normal controls in response to glucose deprivation stress. Arch Gen Psychiatry 2007;64:555-564

10 Perl O, Strous RD, Dranikov A, Chen R, Fuchs S: Low levels of $\alpha_{7}$-nicotinic acetylcholine receptor mRNA on peripheral blood lymphocytes in schizophrenia and its association with illness severity. Neuropsychobiology 2006;53:88-93.

11 Sanders AR, Göring HH, Duan J, Drigalenko EI, Moy W, Freda J, He D, Shi J; MGS, Gejman PV: Transcriptome study of differential expression in schizophrenia. Hum Mol Genet 2013;22:5001-5014.

12 Yao Y, Schröder J, Karlsson H: Verification of proposed peripheral biomarkers in mononuclear cells of individuals with schizophrenia. J Psychiatr Res 2008;42:639-643.

13 Maes OC, Xu S, Yu B, Chertkow HM, Wang E, Schipper HM: Transcriptional profiling of Alzheimer blood mononuclear cells by microarray. Neurobiol Aging 2007;28:17951809.
Exon Array Biomarkers for the

Differential Diagnosis of SZ and BD
Mol Neuropsychiatry 2017;3:197-213 DOI: $10.1159 / 000485800$ 


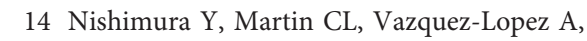
Spence SJ, Alvarez-Retuerto AI, Sigman M, Steindler C, Pellegrini S, Schanen NC, Warren ST, et al: Genome-wide expression profiling of lymphoblastoid cell lines distinguishes different forms of autism and reveals shared pathways. Hum Mol Genet 2007;16:1682-1698.

-15 Giannone S, Strippoli P, Vitale L, Casadei R, Canaider S, Lenzi L, D’Addabbo P, Frabetti F, Facchin F, Farina A, et al: Gene expression profile analysis in human $\mathrm{T}$ lymphocytes from patients with Down syndrome. Ann Hum Genet 2004;68:546-554.

-16 Tang Y, Gilbert DL, Glauser TA, Hershey AD, Sharp FR: Blood gene expression profiling of neurologic diseases: a pilot microarray study. Arch Neurol 2005;62:210-215.

17 Borovecki F, Lovrecic L, Zhou J, Jeong H, Then F, Rosas HD, Hersch SM, Hogarth P, Bouzou B, Jensen RV, et al: Genome-wide expression profiling of human blood reveals biomarkers for Huntington's disease. Proc Natl Acad Sci USA 2005;102:11023-11028.

18 Vawter MP, Harvey PD, DeLisi LE: Dysregulation of X-linked gene expression in Klinefelter's syndrome and association with verbal cognition. Am J Med Genet B Neuropsychiatr Genet 2007;144B:728-734.

-19 Bomprezzi R, Ringnér M, Kim S, Bittner ML, Khan J, Chen Y, Elkahloun A, Yu A, Bielekova B, Meltzer PS, et al: Gene expression profile in multiple sclerosis patients and healthy controls: identifying pathways relevant to disease. Hum Mol Genet 2003;12: 2191-2199.

20 Philibert RA, Ryu GY, Yoon JG, Sandhu H, Hollenbeck N, Gunter T, Barkhurst A, Adams W, Madan A: Transcriptional profiling of subjects from the Iowa adoption studies. Am J Med Genet B Neuropsychiatr Genet 2007; 144B:683-690.

-21 Philibert RA, Crowe R, Ryu GY, Yoon JG, Secrest D, Sandhu H, Madan A: Transcriptional profiling of lymphoblast lines from subjects with panic disorder. Am J Med Genet B Neuropsychiatr Genet 2007;144B:674-682.

-22 Segman RH, Shefi N, Goltser-Dubner T, Friedman N, Kaminski N, Shalev AY: Peripheral blood mononuclear cell gene expression profiles identify emergent post-traumatic stress disorder among trauma survivors. Mol Psychiatry 2005;10:500-513, 425.

-23 Cole SW, Hawkley LC, Arevalo JM, Sung CY, Rose RM, Cacioppo JT: Social regulation of gene expression in human leukocytes. Genome Biol 2007;8:R189.

24 Liew CC, Ma J, Tang HC, Zheng R, Dempsey AA: The peripheral blood transcriptome dynamically reflects system wide biology: a potential diagnostic tool. J Lab Clin Med 2006; 147:126-132.

25 Weber MD, Godbout JP, Sheridan JF: Repeated social defeat, neuroinflammation, and behavior: monocytes carry the signal. Neuropsychopharmacology 2017;42:46-61.

-26 Gelderblom M, Leypoldt F, Steinbach K, Behrens D, Choe CU, Siler DA, Arumugam TV,
Orthey E, Gerloff C, Tolosa E, et al: Temporal and spatial dynamics of cerebral immune cell accumulation in stroke. Stroke 2009;40:18491857.

27 Downes CE, Crack PJ: Neural injury following stroke: are Toll-like receptors the link between the immune system and the CNS? Br J Pharmacol 2010;160:1872-1888.

28 Brea D, Sobrino T, Ramos-Cabrer P, Castillo $\mathrm{J}$ : Inflammatory and neuroimmunomodulatory changes in acute cerebral ischemia. Cerebrovasc Dis 2009;27(suppl 1):48-64.

29 Rollins B, Martin MV, Morgan L, Vawter MP: Analysis of whole genome biomarker expression in blood and brain. Am J Med Genet B Neuropsychiatr Genet 2010;153B:919-936.

- 30 Sekar A, Bialas AR, de Rivera H, Davis A, Hammond TR, Kamitaki N, Tooley K, Presumey J, Baum M, Van Doren V, et al: Schizophrenia risk from complex variation of complement component 4. Nature 2016;530:177183.

31 Morgan LZ, Rollins B, Sequeira A, Byerley W, DeLisi LE, Schatzberg AF, Barchas JD, Myers RM, Watson SJ, Akil H, et al: Quantitative trait locus and brain expression of HLADPA1 offers evidence of shared immune alterations in psychiatric disorders. Microarrays (Basel) 2016;5:6.

32 Vawter MP, Ferran E, Galke B, Cooper K, Bunney WE, Byerley W: Microarray screening of lymphocyte gene expression differences in a multiplex schizophrenia pedigree. Schizophr Res 2004;67:41-52.

-33 Glatt SJ, Chandler SD, Bousman CA, Chana G, Lucero GR, Tatro E, May T, Lohr JB, Kremen WS, Everall IP, et al: Alternatively spliced genes as biomarkers for schizophrenia, bipolar disorder and psychosis: a blood-based spliceomeprofiling exploratory study. Curr Pharmacogenomics Person Med 2009;7:164-188.

34 Glatt SJ, Stone WS, Nossova N, Liew CC, Seidman LJ, Tsuang MT: Similarities and differences in peripheral blood gene-expression signatures of individuals with schizophrenia and their first-degree biological relatives. Am J Med Genet B Neuropsychiatr Genet 2011; 156B:869-887.

35 Hess JL, Tylee DS, Barve R, de Jong S, Ophoff RA, Kumarasinghe N, Tooney P, Schall U, Gardiner E, Beveridge NJ, et al: Transcriptome-wide mega-analyses reveal joint dysregulation of immunologic genes and transcription regulators in brain and blood in schizophrenia. Schizophr Res 2016;176:114-124.

36 Horváth S, Mirnics K: Immune system disturbances in schizophrenia. Biol Psychiatry 2014; 75:316-323.

37 Kumarasinghe N, Beveridge NJ, Gardiner E, Scott RJ, Yasawardene S, Perera A, Mendis J, Suriyakumara K, Schall U, Tooney PA: Gene expression profiling in treatment-naive schizophrenia patients identifies abnormalities in biological pathways involving $A K T 1$ that are corrected by antipsychotic medication. Int J Neuropsychopharmacol 2013;16: 1483-1503.
$38 \mathrm{Wu}$ JQ, Green MJ, Gardiner EJ, Tooney PA, Scott RJ, Carr VJ, Cairns MJ: Altered neural signaling and immune pathways in peripheral blood mononuclear cells of schizophrenia patients with cognitive impairment: a transcriptome analysis. Brain Behav Immun 2016;53:194-206.

-39 Xu Y, Yao Shugart Y, Wang G, Cheng Z, Jin C, Zhang K, Wang J, Yu H, Yue W, Zhang F, et al: Altered expression of mRNA profiles in blood of early-onset schizophrenia. Sci Rep 2016;6:16767.

40 Martin MV, Rollins B, Sequeira PA, Mesén A, Byerley W, Stein R, Moon EA, Akil H, Jones EG, Watson SJ, et al: Exon expression in lymphoblastoid cell lines from subjects with schizophrenia before and after glucose deprivation. BMC Med Genomics 2009;2:62.

41 Vawter MP, Mamdani F, Macciardi F: An integrative functional genomics approach for discovering biomarkers in schizophrenia. Brief Funct Genomics 2011;10:387-399.

42 Mamdani F, Martin MV, Lencz T, Rollins B, Robinson DG, Moon EA, Malhotra AK, Vawter MP: Coding and noncoding gene expression biomarkers in mood disorders and schizophrenia. Dis Markers 2013;35:11-21.

43 Bemmo A, Benovoy D, Kwan T, Gaffney DJ, Jensen RV, Majewski J: Gene expression and isoform variation analysis using Affymetrix Exon Arrays. BMC Genomics 2008;9:529.

44 Benovoy D, Kwan T, Majewski J: Effect of polymorphisms within probe-target sequences on olignonucleotide microarray experiments. Nucleic Acids Res 2008;36:4417-4423.

45 Duan S, Zhang W, Bleibel WK, Cox NJ, Dolan ME: SNPinProbe_1.0: a database for filtering out probes in the Affymetrix GeneChip human exon $1.0 \mathrm{ST}$ array potentially affected by SNPs. Bioinformation 2008;2:469-470.

-46 Heinzen EL, Ge D, Cronin KD, Maia JM, Shianna KV, Gabriel WN, Welsh-Bohmer KA, Hulette CM, Denny TN, Goldstein DB: Tissue-specific genetic control of splicing: implications for the study of complex traits. PLoS Biol 2008;6:e1.

47 Kwan T, Benovoy D, Dias C, Gurd S, Provencher C, Beaulieu P, Hudson TJ, Sladek R, Majewski J: Genome-wide analysis of transcript isoform variation in humans. Nat Genet 2008;40:225-231.

48 Sequeira A, Meng F, Rollins B, Myers RM, Jones EG, Watson SJ, Akil H, Schatzberg AF, Barchas J, Bunney WE, et al: Coding SNPs included in exon arrays for the study of psychiatric disorders. Mol Psychiatry 2008;13:363-365.

49 Duan S, Huang RS, Zhang W, Mi S, Bleibel WK, Kistner EO, Cox NJ, Dolan ME: Expression and alternative splicing of folate pathway genes in HapMap lymphoblastoid cell lines. Pharmacogenomics 2009;10:549-563.

50 Fraser HB, Xie X: Common polymorphic transcript variation in human disease. $\mathrm{Ge}$ nome Res 2009;19:567-575.

51 Gamazon ER, Zhang W, Dolan ME, Cox NJ: Comprehensive survey of SNPs in the Affymetrix exon array using the 1,000 Genomes dataset. PLoS One 2010;5:e9366. 
-52 Gamazon ER, Zhang W, Konkashbaev A, Duan S, Kistner EO, Nicolae DL, Dolan ME, Cox NJ: SCAN: SNP and copy number annotation. Bioinformatics 2010;26:259-262.

-53 Pradervand S, Paillusson A, Thomas J, Weber J, Wirapati P, Hagenbüchle O, Harshman K: Affymetrix Whole-Transcript Human Gene 1.0 ST array is highly concordant with standard $3^{\prime}$ expression arrays. Biotechniques 2008;44:759-762.

54 Agarwal A, Koppstein D, Rozowsky J, Sboner A, Habegger L, Hillier LW, Sasidharan R, Reinke V, Waterston RH, Gerstein M: Comparison and calibration of transcriptome data from RNA-Seq and tiling arrays. BMC Genomics 2010;11:383.

-55 Bradford JR, Hey Y, Yates T, Li Y, Pepper SD, Miller CJ: A comparison of massively parallel nucleotide sequencing with oligonucleotide microarrays for global transcription profiling. BMC Genomics 2010;11:282.

56 Liu S, Lin L, Jiang P, Wang D, Xing Y: A comparison of RNA-Seq and high-density exon array for detecting differential gene expression between closely related species. Nucleic Acids Res 2011;39:578-588.

57 Richard H, Schulz MH, Sultan M, Nürnberger A, Schrinner S, Balzereit D, Dagand E, Rasche A, Lehrach H, Vingron M, et al: Prediction of alternative isoforms from exon expression levels in RNA-Seq experiments. Nucleic Acids Res 2010;38:e112.

-58 Kapur K, Jiang H, Xing Y, Wong WH: Crosshybridization modeling on Affymetrix exon arrays. Bioinformatics 2008;24:2887-2893.

-59 Kapur K, Xing Y, Ouyang Z, Wong WH: Exon arrays provide accurate assessments of gene expression. Genome Biol 2007;8:R82.

-60 Xing Y, Kapur K, Wong WH: Probe selection and expression index computation of Affymetrix Exon Arrays. PLoS One 2006;1:e88.

-61 Xing Y, Ouyang Z, Kapur K, Scott MP, Wong $\mathrm{WH}$ : Assessing the conservation of mammalian gene expression using high-density exon arrays. Mol Biol Evol 2007;24:1283-1285.

-62 Xing Y, Stoilov P, Kapur K, Han A, Jiang H, Shen S, Black DL, Wong WH: MADS: a new and improved method for analysis of differential alternative splicing by exon-tiling microarrays. RNA 2008;14:1470-1479.

-63 Lin L, Liu S, Brockway H, Seok J, Jiang P, Wong WH, Xing Y: Using high-density exon arrays to profile gene expression in closely related species. Nucleic Acids Res 2009;37:e90.

-64 Shen S, Warzecha CC, Carstens RP, Xing Y: MADS+: discovery of differential splicing events from Affymetrix exon junction array data. Bioinformatics 2010;26:268-269.

- $65 \mathrm{Xu} \mathrm{W,} \mathrm{Seok} \mathrm{J,} \mathrm{Mindrinos} \mathrm{MN,} \mathrm{Schweitzer}$ AC, Jiang H, Wilhelmy J, Clark TA, Kapur K, Xing Y, Faham M, et al: Human transcriptome array for high-throughput clinical studies. Proc Natl Acad Sci USA 2011;108:37073712.

66 Duan S, Huang RS, Zhang W, Bleibel WK, Roe CA, Clark TA, Chen TX, Schweitzer AC,
Blume JE, Cox NJ, et al: Genetic architecture of transcript-level variation in humans. Am J Hum Genet 2008;82:1101-1113.

67 Pepe MS: The Statistical Evaluation of Medical Tests for Classification and Prediction. Oxford statistical science series. Oxford/New York, Oxford University Press, 2003, xvi, p 302.

68 Mamdani F, Rollins B, Morgan L, Myers RM, Barchas JD, Schatzberg AF, Watson SJ, Akil H, Potkin SG, Bunney WE, et al: Variable telomere length across post-mortem human brain regions and specific reduction in the hippocampus of major depressive disorder. Transl Psychiatry 2015;5:e636.

69 Li MJ, Liu Z, Wang P, Wong MP, Nelson MR, Kocher JP, Yeager M, Sham PC, Chanock SJ, Xia Z, et al: GWASdb v2: an update database for human genetic variants identified by genome-wide association studies. Nucleic Acids Res 2016;44:D869-D876.

70 Hawrylycz MJ, Lein ES, Guillozet-Bongaarts AL, Shen EH, Ng L, Miller JA, van de Lagemaat LN, Smith KA, Ebbert A, Riley ZL, et al: An anatomically comprehensive atlas of the adult human brain transcriptome. Nature 2012;489:391-399.

71 Ramos EI, Bien-Willner GA, Li J, Hughes AE, Giacalone J, Chasnoff S, Kulkarni S, Parmacek M, Cole FS, Druley TE: Genetic variation in MKL2 and decreased downstream PCTAIRE1 expression in extreme, fatal primary human microcephaly. Clin Genet 2014; 85:423-432.

72 Munkholm K, Peijs L, Kessing LV, Vinberg M: Reduced mRNA expression of PTGDS in peripheral blood mononuclear cells of rapidcycling bipolar disorder patients compared with healthy control subjects. Int J Neuropsychopharmacol 2014;18:pyu101.

73 Le-Niculescu H, Balaraman Y, Patel SD, Ayalew M, Gupta J, Kuczenski R, Shekhar A, Schork N, Geyer MA, Niculescu AB: Convergent functional genomics of anxiety disorders: translational identification of genes, biomarkers, pathways and mechanisms. Transl Psychiatry 2011;1:e9.

74 Liu Y, McNamara RK: Elevated delta-6 desaturase (FADS2) gene expression in the prefrontal cortex of patients with bipolar disorder. J Psychiatr Res 2011;45:269-272.

75 Liu Y, Jandacek R, Rider T, Tso P, McNamara RK: Elevated delta- 6 desaturase (FADS2) expression in the postmortem prefrontal cortex of schizophrenic patients: relationship with fatty acid composition. Schizophr Res 2009; 109:113-120.

76 Evans SJ, Prossin AR, Harrington GJ, Kamali M, Ellingrod VL, Burant CF, McInnis MG: Fats and factors: lipid profiles associate with personality factors and suicidal history in bipolar subjects. PLoS One 2012;7:e29297.

77 Schizophrenia Working Group of the Psychiatric Genomics Consortium: Biological insights from 108 schizophrenia-associated genetic loci. Nature 2014;511:421-427.

78 Hou L, Bergen SE, Akula N, Song J, Hultman
CM, Landén M, Adli M, Alda M, Ardau R, Arias B, et al: Genome-wide association study of 40,000 individuals identifies two novel loci associated with bipolar disorder. Hum Mol Genet 2016;25:3383-3394.

79 Purcell SM, Wray NR, Stone JL, Visscher PM, O’Donovan MC, Sullivan PF, Sklar P: Common polygenic variation contributes to risk of schizophrenia and bipolar disorder. Nature 2009;460:748-752.

80 Fromer M, Roussos P, Sieberts SK, Johnson JS, Kavanagh DH, Perumal TM, Ruderfer DM, Oh EC, Topol A, Shah HR, et al: Gene expression elucidates functional impact of polygenic risk for schizophrenia. Nat Neurosci 2016;19:1442-1453.

81 Chan MK, Gottschalk MG, Haenisch F, Tomasik J, Ruland T, Rahmoune H, Guest PC, Bahn S: Applications of blood-based protein biomarker strategies in the study of psychiatric disorders. Prog Neurobiol 2014;122:4572.

82 Chan MK, Krebs MO, Cox D, Guest PC, Yolken RH, Rahmoune H, Rothermundt M, Steiner J, Leweke FM, van Beveren NJ, et al: Development of a blood-based molecular biomarker test for identification of schizophrenia before disease onset. Transl Psychiatry 2015;5:e601.

83 Haenisch F, Cooper JD, Reif A, Kittel-Schneider S, Steiner J, Leweke FM, Rothermundt M, van Beveren NJ, Crespo-Facorro B, Niebuhr DW, et al: Towards a blood-based diagnostic panel for bipolar disorder. Brain Behav Immun 2016;52:49-57.

-84 Scarr E, Millan MJ, Bahn S, Bertolino A, Turck CW, Kapur S, Möller HJ, Dean B: Biomarkers for psychiatry: the journey from fantasy to fact, a report of the 2013 CINP Think Tank. Int J Neuropsychopharmacol 2015; 18:pyv042.

85 Tomasik J, Schwarz E, Guest PC, Bahn S: Blood test for schizophrenia. Eur Arch Psychiatry Clin Neurosci 2012;262(suppl 2): S79-S83.

-86 Zhang Y, Chen K, Sloan SA, Bennett ML, Scholze AR, O'Keeffe S, Phatnani HP, Guarnieri P, Caneda C, Ruderisch N, et al: An RNA-sequencing transcriptome and splicing database of glia, neurons, and vascular cells of the cerebral cortex. J Neurosci 2014;34: 11929-11947.

87 Anand A, McClintick JN, Murrell J, Karne H, Nurnberger JI, Edenberg HJ: Effects of lithium monotherapy for bipolar disorder on gene expression in peripheral lymphocytes. Mol Neuropsychiatry 2016;2:115-123.

88 Cloutier M, Aigbogun MS, Guerin A, Nitulescu R, Ramanakumar AV, Kamat SA, DeLucia M, Duffy R, Legacy SN, Henderson C, et al: The economic burden of schizophrenia in the United States in 2013. J Clin Psychiatry 2016; 77:764-771.

89 Dilsaver SC: An estimate of the minimum economic burden of bipolar I and II disorders in the United States: 2009. J Affect Disord 2011;129:79-83.
Exon Array Biomarkers for the

Differential Diagnosis of SZ and BD
Mol Neuropsychiatry 2017;3:197-213 DOI: $10.1159 / 000485800$ 